\title{
The Flögel-three-component reaction with dicarboxylic acids - an approach to bis( $\beta$-alkoxy- $\beta$ - ketoenamides) for the synthesis of complex pyridine and pyrimidine derivatives
}

\author{
Mrinal K. Bera ${ }^{1,2}$, Moisés Domínguez ${ }^{1}$, Paul Hommes ${ }^{1}$ \\ and Hans-Ulrich Reissig ${ }^{* 1}$
}

\section{Full Research Paper}

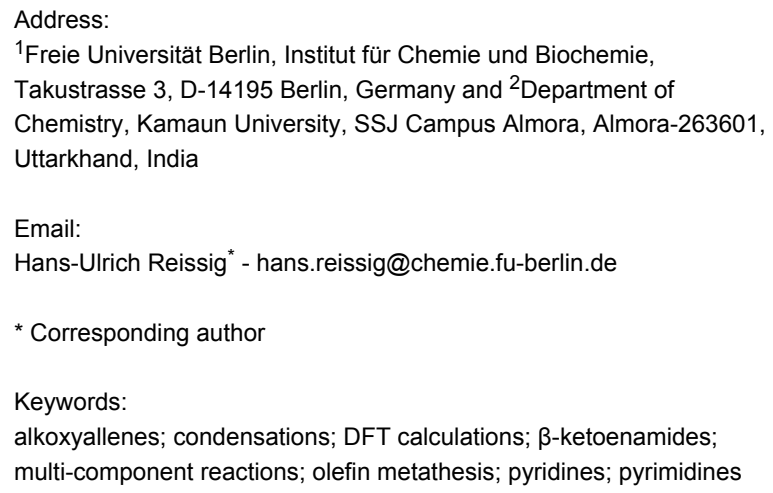

${ }^{1}$ Freie Universität Berlin, Institut für Chemie und Biochemie, Takustrasse 3, D-14195 Berlin, Germany and ${ }^{2}$ Department of Chemistry, Kamaun University, SSJ Campus Almora, Almora-263601, Uttarkhand, India

Email:

Hans-Ulrich Reissig* - hans.reissig@chemie.fu-berlin.de

* Corresponding author

Keywords:

alkoxyallenes; condensations; DFT calculations; $\beta$-ketoenamides;

multi-component reactions; olefin metathesis; pyridines; pyrimidines

Beilstein J. Org. Chem. 2014, 10, 394-404.

doi:10.3762/bjoc. 10.37

Received: 12 November 2013

Accepted: 17 January 2014

Published: 13 February 2014

This article is part of the Thematic Series "Multicomponent reactions II".

Guest Editor: T. J. J. Müller

(c) 2014 Bera et al; licensee Beilstein-Institut.

License and terms: see end of document.

\begin{abstract}
An extension of the substrate scope of the Flögel-three-component reaction of lithiated alkoxyallenes, nitriles and carboxylic acids is presented. The use of dicarboxylic acids allowed the preparation of symmetrical bis( $\beta$-ketoenamides) from simple starting materials in moderate yields. Cyclocondensations of these enamides to 4-hydroxypyridine derivatives or to functionalized pyrimidines efficiently provided symmetrically and unsymmetrically substituted fairly complex (hetero)aromatic compounds containing up to six conjugated aryl and hetaryl groups. In addition, subsequent functionalizations of the obtained heterocycles by palladiumcatalyzed couplings or by oxidations are reported. We also describe the simple synthesis of a structurally interesting macrocyclic bispyrimidine derivative incorporating a 17-membered ring, whose configuration was elucidated by DFT calculations and by subsequent reactions.
\end{abstract}

\section{Introduction}

Multicomponent reactions (MCRs) generally allow a diversityoriented fast and efficient access to complex synthetic intermediates and are thus powerful tools for the assembly of smallmolecule libraries [1,2]. MCRs leading to functionalized $N$-heterocycles [3-7] have long been known before the general concept of MCRs was introduced, e.g. the Hantzsch dihydro-

pyridine synthesis [8] or the Biginelli reaction [9] leading to dihydropyrimidinones or the corresponding dihydropyrimidinethiones. Due to their general importance (e.g. as biologically active compounds) the development of efficient protocols for the preparation of functionalized pyridine [10-20] and pyrimidine derivatives [21-33], in particular by MCRs, is of 
permanent high interest. In the course of exploring the reactivity of alkoxyallenes and their utilization as $\mathrm{C}-3$ building blocks [34-37] our group developed a highly flexible method to synthesize $\beta$-alkoxy- $\beta$-ketoenamides of type 1 that are remarkably versatile cyclization precursors for the synthesis of functionalized heterocycles such as 4-hydroxypyridines [38-44], furopyridines [45], 5-acetyloxazoles [46,47], pyrimidines $[43,48,49]$ and their corresponding $N$-oxides [50] (Scheme 1) This approach - discovered and mechanistically elucidated by Oliver Flögel - features a three-component reaction that employs alkoxyallenes, nitriles and carboxylic acids: upon treatment with $n$-butyllithium the allene is lithiated in $\alpha$-position to the alkoxy moiety; the addition of a nitrile as electrophile to this highly reactive nucleophile results in the formation of an iminoallene adduct [38] that is protonated and subsequently acylated by the addition of a carboxylic acid furnishing a $\beta$-alkoxy- $\beta$-ketoenamide 1. A detailed mechanistic proposal for this reaction has been disclosed in previous reports [38,39].

Our earlier investigations revealed that this method tolerates a broad variety of differently substituted starting materials - inter alia (het-)aromatic and (branched) aliphatic nitriles and carboxylic acids. It is also noteworthy to mention that the configurational integrity of enantiopure $\alpha$-chiral carboxylic acids and/or nitriles is retained during this reaction [40]. In the present report we describe our efforts to further broaden the substrate scope of this multicomponent reaction and the subsequent cyclizations by employing aromatic dicarboxylic acids. This extension should allow a rapid access to fairly complex heteroaromatic systems containing up to six conjugated aryl and hetaryl groups. Complementary examples employing aromatic dinitriles in this Flögel-three-component reaction have previously been presented [39].

\section{Results and Discussion}

As typical model substrates we chose to employ isophthalic acid (11) and diphenic acid (12) in combination with methoxyallene (7), pivalonitrile (9) and thiophene-2-carbonitrile (10) in the three-component reaction (Scheme 2). Gratifyingly we were able to isolate the expected bis( $\beta$-ketoenamides) 13-15 in reasonable yields of $15-28 \%$. Taking the number of individual steps into account (six new bonds are formed for<smiles>[R]CC(=O)c1oc([R4])nc1[R]</smiles> 


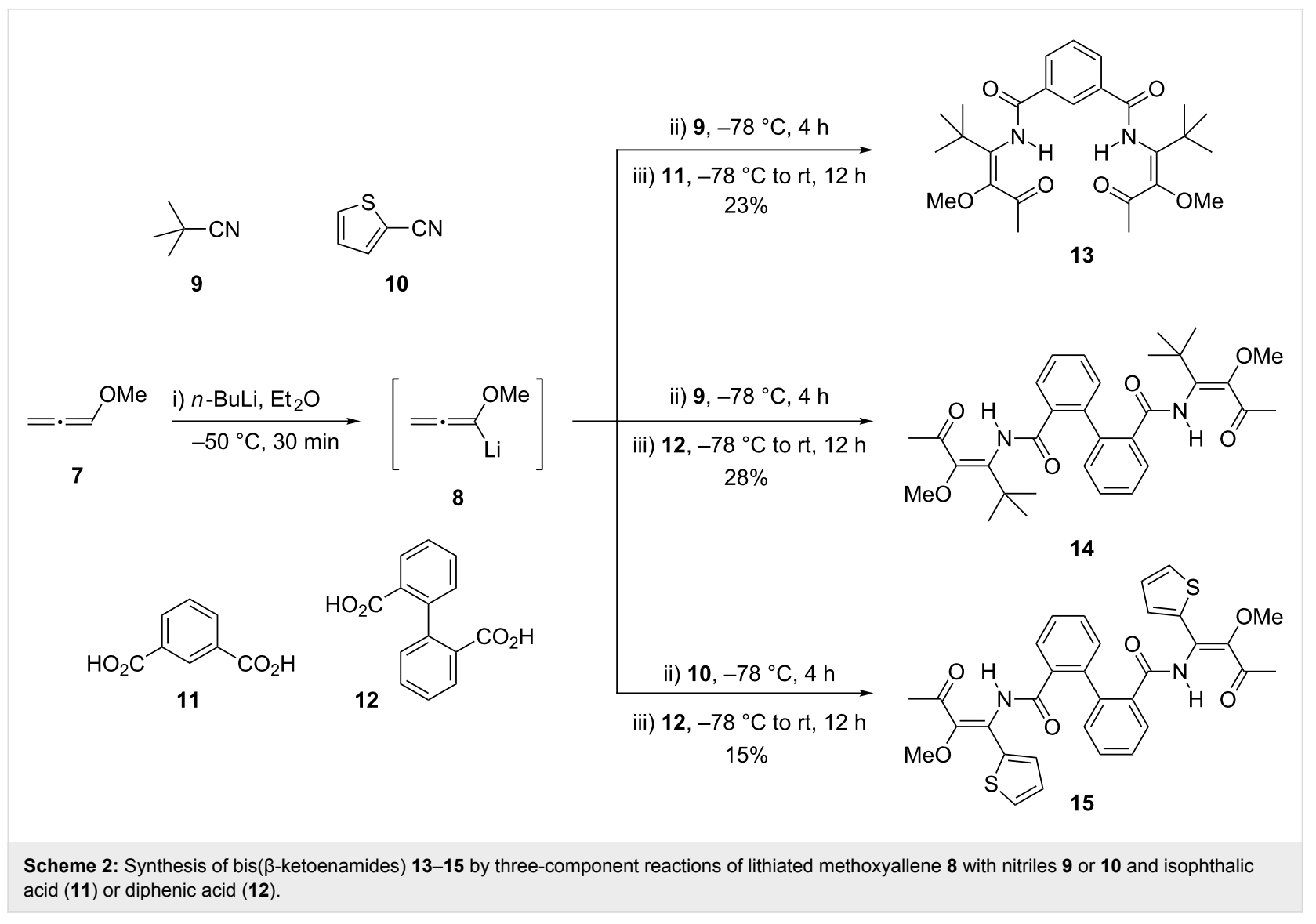

each product) and considering possible (unknown) side reactions these yields are quite satisfactory. In analogy to our previously published results $[38,51,52]$ the double bond geometry of the enamide moiety is likely to be $E$-configured as shown in Scheme 2, allowing an intramolecular hydrogen bridge between the amide $\mathrm{NH}$ and the $\beta$-carbonyl group. However, we did not further investigate the nature of the double bond geometry, since it was irrelevant for the planed subsequent cyclization reactions where the (Lewis-)acidic conditions allow a facile isomerization of $E$ - and $Z$-configured enamide moieties [51,52], finally leading to identical products.

After these successful multicomponent reactions we investigated the intramolecular condensations of the bis( $\beta$-ketoenamides) 13-15 to pyridine and pyrimidine derivatives. Enamides 13 and 14 were treated with trimethylsilyl trifluoromethanesulfonate (TMSOTf) and triethylamine to provide the bis(4-hydoxypyridines) $\mathbf{1 6}$ in 50\% yield and 18a in 60\% yield, respectively (Scheme 3 ). A mechanistic proposal for this aldol type condensation has been presented in a previous report [53]. For precursor 14 partial monocyclization was observed under the applied conditions, affording in $18 \%$ yield 4-hydroxypyridine $18 \mathrm{~b}$ with a retained $\beta$-ketoenamide moiety. Treatment of compounds $16,18 \mathrm{a}$ and $\mathbf{1 8 b}$ with sodium hydride followed by nonafluorobutanesulfonyl fluoride $(\mathrm{NfF})$ provided the corresponding sulfonates 17, 19 and 20 in yields in the range of $60-72 \%$. Pyrid-4-yl nonaflates are excellent precursors for transition metal-catalyzed cross-coupling reactions [42,54-58], which was demonstrated here by the successful Suzuki coupling of bisnonaflate 19 with $(E)$-styrylboronic acid and the Stille coupling of 19 with 2-(tributylstannyl)thiophene. Albeit the expected twofold coupling products $\mathbf{2 1}$ and $\mathbf{2 2}$ were obtained in only moderate yields, the presented approach nevertheless features a quite rapid access to these fairly complex heteroaromatic systems containing six conjugated aryl and hetaryl groups. Upon excitation with UV light (253 nm) compound 22 shows fluorescence with a maximum intensity at $378 \mathrm{~nm}$ (see Supporting Information File 1 for details). The photophysical properties of structurally related pyridine-thiophene conjugates were recently investigated in detail $[55,57,58]$.

Next, we investigated the cyclocondensation of bis( $\beta$-ketoenamides) 13-15 to pyrimidines (Scheme 4) using ammonium acetate as ammonia source. Initially we subjected enamide $\mathbf{1 3}$ to conditions that had been optimized for mono- $\beta$-ketoenamides $[48,49]$, in this case resulting in incomplete conversion: after heating 13 with 8 equiv of ammonium acetate in a sealed tube we obtained a 1:1 mixture of bis(pyrimidine) derivative 23a and 


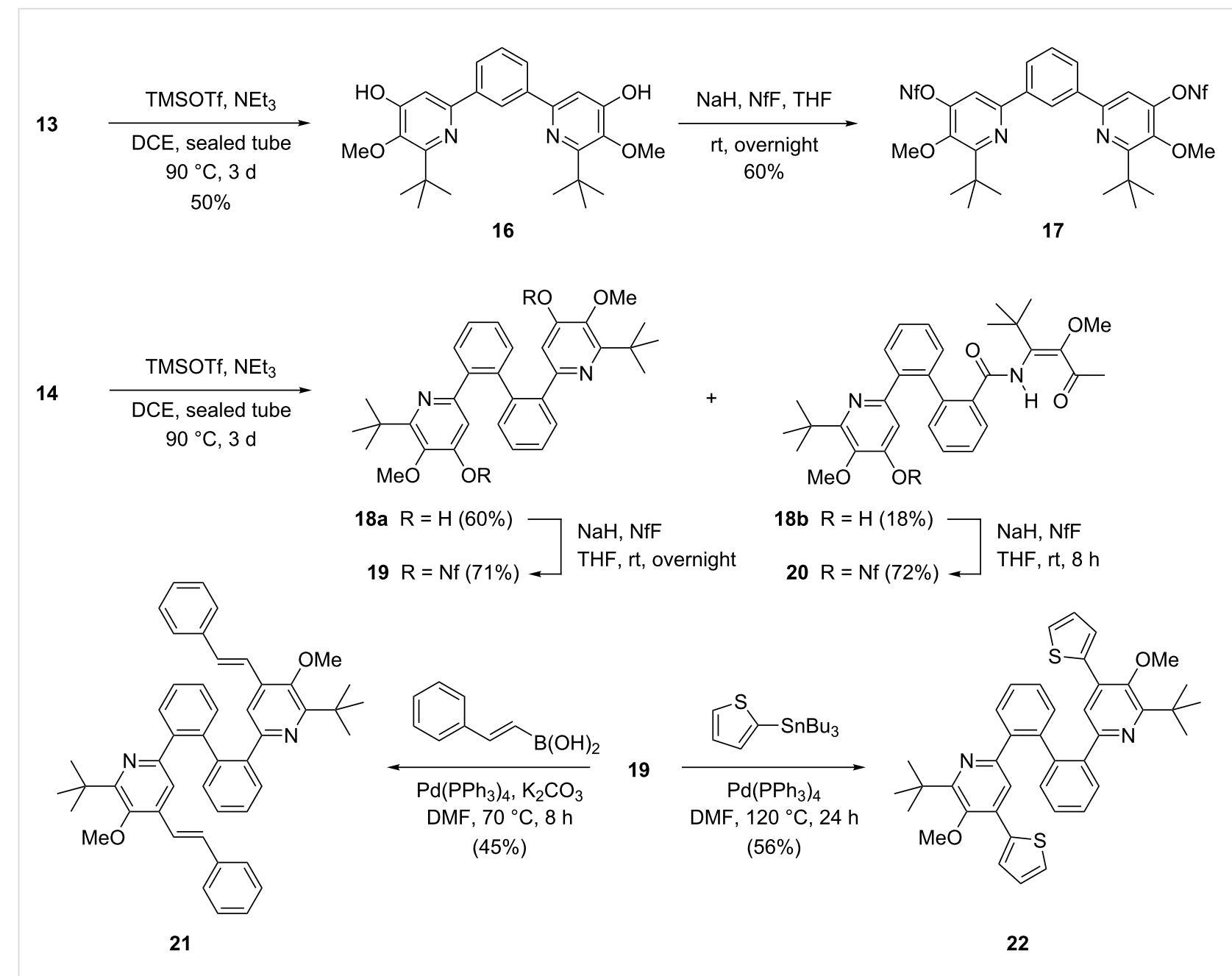

Scheme 3: Cyclocondensations of $\beta$-ketoenamides 13 and 14 to 4-hydroxypyridines $16,18 \mathrm{a}$ and $18 \mathrm{~b}$, their subsequent nonaflations and palladiumcatalyzed coupling reactions of 19 leading to compounds 21 and 22 . $\mathrm{NfF}=\mathrm{C}_{4} \mathrm{~F}_{9} \mathrm{SO}_{2} \mathrm{~F}$

pyrimidine $\mathbf{2 3 b}$ still containing one $\beta$-ketoenamide unit with an overall yield of $68 \%$. However, full conversion of 13 into 23a was achieved by increasing the amount of ammonium acetate to 16 equiv and using a higher reaction temperature, raising the yield of 23a from $34 \%$ to $55 \%$ yield. When enamide 14 was cyclized under these optimized conditions the conversion was nevertheless incomplete giving the desired bis(pyrimidine) derivative $24 \mathrm{a}$ in $56 \%$ yield and the corresponding monopyrimidine 24b in $23 \%$ yield. For enamide 15 however, the cyclization was complete under these conditions furnishing bis(pyrimidine) derivative $\mathbf{2 5}$ as a single product in $60 \%$ yield.

Although initially not desired the incomplete conversions of the bis( $\beta$-ketoenamides) leading to mono-pyridine derivatives such as $\mathbf{1 8 b}$ or to mono-pyrimidine derivatives like $\mathbf{2 3 b}$ and $\mathbf{2 4 b}$ provided new synthetic options to construct unsymmetrically substituted mixed heteroaromatic systems. As an example we used mono-pyrimidine derivative $\mathbf{2 4 b}$ and cyclized its $\beta$-ketoen- amide moiety by treatment with TMSOTf and triethylamine. Pyrimidine/pyridinol derivative $\mathbf{2 6}$ was isolated in $\mathbf{7 9 \%}$ yield (Scheme 5) and subsequently converted into the corresponding nonaflate 27 in $70 \%$ yield.

As recently described, $\beta$-alkoxy- $\beta$-ketoenamides may also be directly cyclized to pyrimidine- $N$-oxides under mild conditions if hydroxylamine hydrochloride is used as reagent [50]. Accordingly, the reactions of $\beta$-ketoenamides $\mathbf{1 4}$ and $\mathbf{2 0}$ with hydroxylamine hydrochloride provided the symmetric bis(pyrimidine- $N$ oxide) $\mathbf{2 8}$ in $39 \%$ yield or the mono-pyrimidine- $N$-oxide $\mathbf{3 0}$ in $54 \%$ yield (Scheme 6 ). The acetoxylation of 2- and 4-alkyl substituted pyridine- $N$-oxides by treatment with acetic anhydride is known as the Boekelheide rearrangement [59,60]. For pyrimidine- $N$-oxides however, only few examples of this type of transformation have been reported [50,61-65]. Therefore we were pleased to find that upon treatment with acetic anhydride the obtained pyrimidine- $N$-oxides 28 and $\mathbf{3 0}$ smoothly under- 


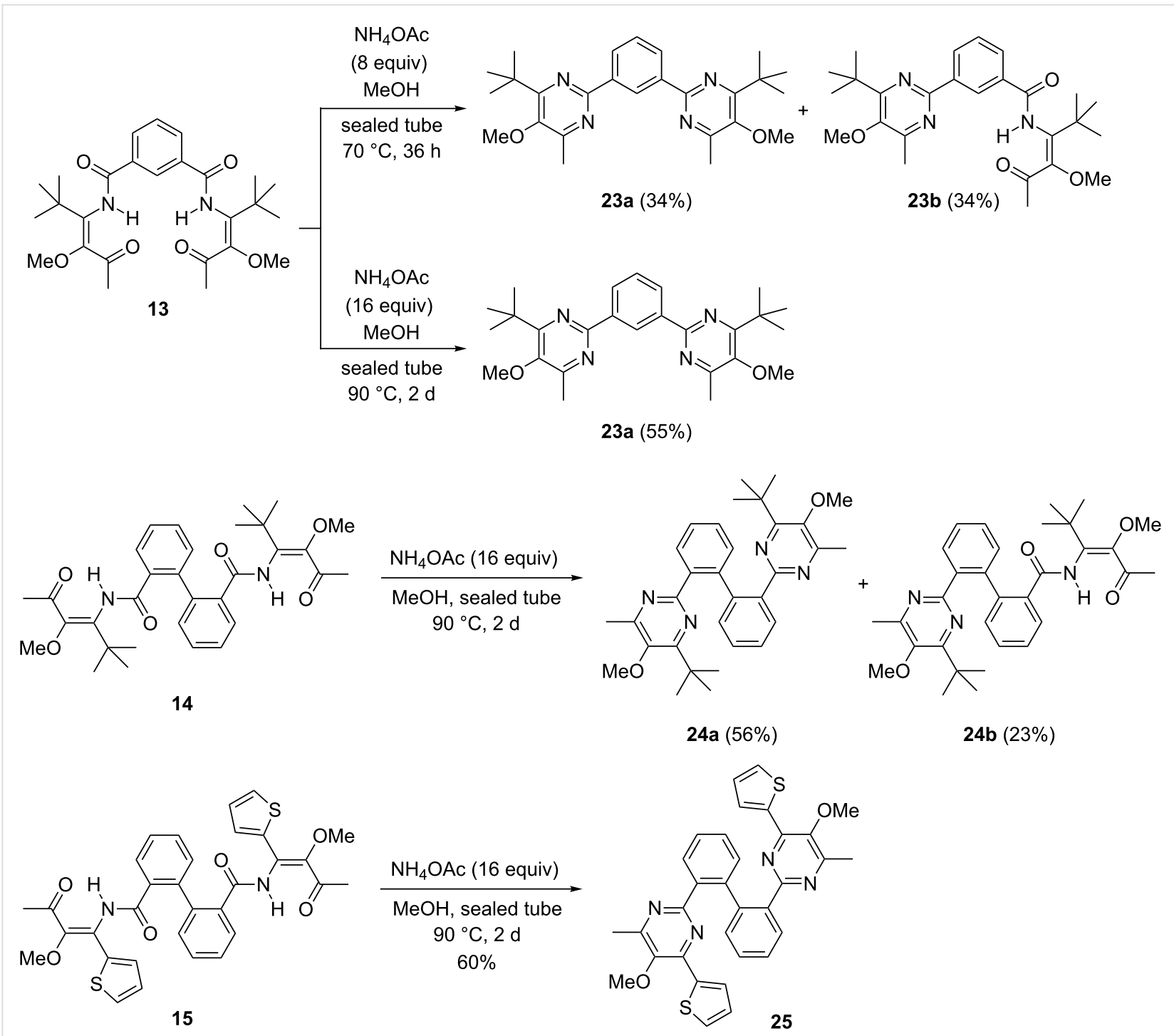

Scheme 4: Cyclocondensations of $\beta$-ketoenamides 13-15 with ammonium acetate to bis(pyrimidine) derivatives 23a, 24a and 25 and mono-pyrimidines $\mathbf{2 3 b}$ and $\mathbf{2 4 b}$.

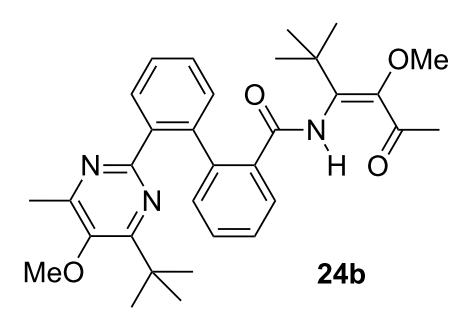

1) TMSOTf, $\mathrm{NEt}_{3}, \mathrm{DCE}$ sealed tube, $90{ }^{\circ} \mathrm{C}, 3 \mathrm{~d}$ $\mathrm{R}=\mathrm{H}, 79 \%$

2) $\mathrm{NaH}, \mathrm{NfF}$

THF, rt, $4 \mathrm{~h}$

$\mathrm{R}=\mathrm{Nf}, 70 \%$

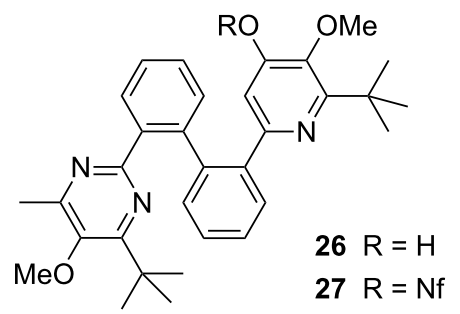

Scheme 5: Conversion of mono-pyrimidine derivative 24b into unsymmetrically substituted biphenylen-bridged pyrimidine/nonafloxypyridine conjugate 27. $\mathrm{NfF}=\mathrm{C}_{4} \mathrm{~F}_{9} \mathrm{SO}_{2} \mathrm{~F}$

went the expected rearrangement to give the acetoxymethylsubstituted pyrimidine derivatives 29 and $\mathbf{3 1}$ in $61 \%$ and 55\% yield, respectively. This approach thus allows the simple func- tionalization of the 4-methyl group of the pyrimidine derivatives and is a very useful tool for the preparation of other compounds. 


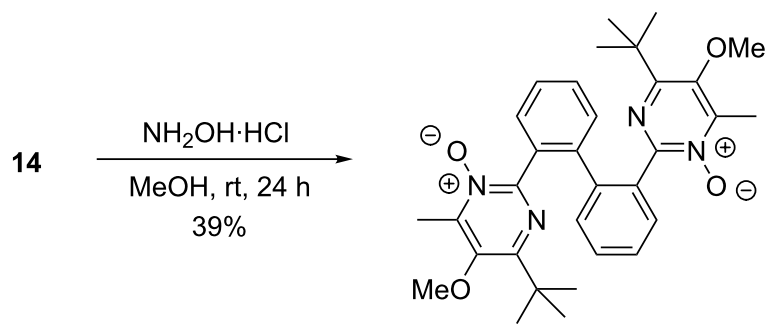

28

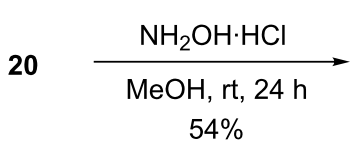

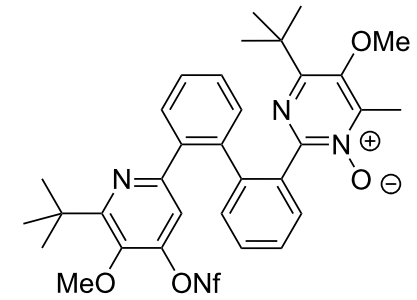

30

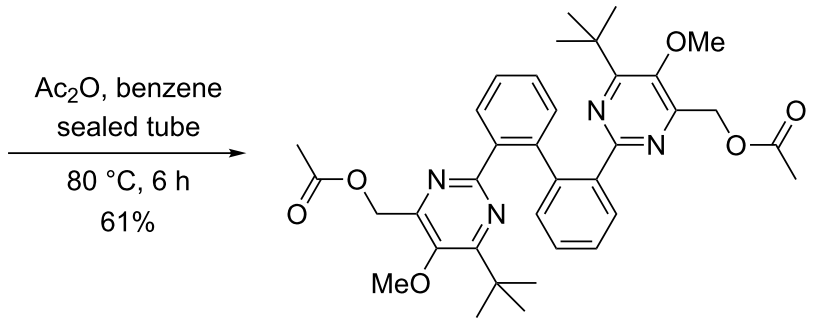

29

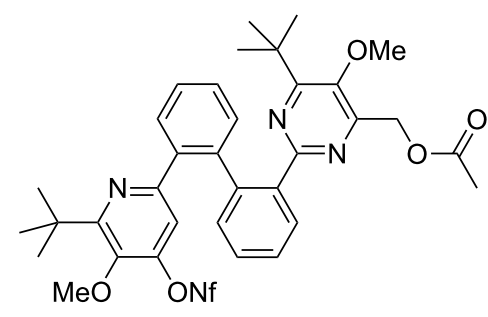

31

Scheme 6: Condensation of $\beta$-ketoenamides 14 and 20 with hydroxylamine hydrochloride to pyridine- $N$-oxides 28 and $\mathbf{3 0}$ and their subsequent Boekelheide rearrangements furnishing functionalized bis(pyrimidine) derivative 29 and pyrimidine/pyridine conjugate 31 .

An alternative option for the side chain functionalization of 4or 6-methyl substituted pyrimidines involves an oxidation with selenium dioxide (Riley oxidation [66-68]). To explore the synthetic potential of the newly prepared compounds we exemplarily oxidized bis(pyrimidine) 23a by this method in order to finally prepare a macrocyclic compound such as $\mathbf{3 4}$ (Scheme 7). Treatment of 23a with an excess of selenium dioxide at $90{ }^{\circ} \mathrm{C}$ resulted in the formation of an inseparable mixture of two different aldehydes (probably the dialdehyde and the monoaldehyde). After reduction of the mixture with sodium borohydride the obtained products could be separated by column chromatography providing the dialcohol 32a in 51\% yield over two steps and the monoalcohol $\mathbf{3 2 b}$ in $25 \%$ yield, respectively. The subsequent O-allylation of 32a furnished bisallyl ether $\mathbf{3 3}$ with 77\% yield that was subjected to a ring closing metathesis (RCM) [69] with Grubbs-II-catalyst smoothly leading to the struc-<smiles>COc1nc(-c2cccc(-c3nc(C)c(OC)c(C(C)(C)C)n3)c2)nc(C)c1C(C)(C)C</smiles>

$23 a$<smiles></smiles>

32a $(51 \%)$<smiles>COc1c(C)nc(-c2cccc(-c3nc(C)c(C(C)(C)C)nc3C(C)(C)C)c2)nc1CO</smiles>

$32 b(25 \%)$

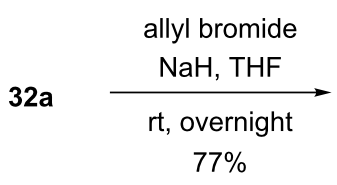<smiles>C=CCOCc1nc(-c2cccc(-c3nc(COCC=C)c(OC)c(C(C)(C)C)n3)c2)nc(C(C)(C)C)c1OC</smiles>

33

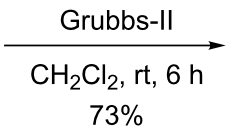<smiles></smiles>

34 
turally interesting macrocyclic compound $\mathbf{3 4}$ in $73 \%$ yield. Compounds of this type - incorporating a 17 -membered ring have the potential to serve as structurally quite unique ligands for a variety of applications, e.g. in catalysis.

With ruthenium-based catalysts bearing $N$-heterocyclic carbene (NHC) ligands, RCM usually delivers macrocyclic olefins as mixtures of $E$ - and $Z$-isomers, in most cases in favor of the $E$-isomer [70-73]. The $E / Z$-ratio is often under thermodynamic control, reflecting the energy difference between the two isomers. According to TLC and NMR spectroscopy, macrocycle 34 was isolated as a single compound. Due to the symmetry of $\mathbf{3 4}$ no couplings of the olefinic protons in its ${ }^{1} \mathrm{H}$ NMR spectrum can be observed. Thus at this stage, we were unable to assign the configuration of the double bond. In lack of suitable crystals for an X-ray analysis, we calculated the energy for the two possible isomers of $\mathbf{3 4}$, suggesting that the $E$-isomer should be considerably more stable than the corresponding $Z$-isomer (Table 1). Using the semi-empirical AM1 method an energy difference of $\Delta E_{Z-E}$ of $28.7 \mathrm{~kJ} / \mathrm{mol}$ was determined. DFT calculations using the B3LYP method with the basis sets 6-31(d) or 6-31G(d,p) both gave a $\Delta E_{Z-E}$ value of $16.4 \mathrm{~kJ} / \mathrm{mol}$. This energy difference may be attributed to the strain of the macrocycle and higher torsion angles between the central benzene unit and the pyrimidine rings for the $Z$-isomer of $\mathbf{3 4}$, resulting in less efficient conjugation of the aromatic $\pi$-systems.
The optimized molecular geometries of E-34 and Z-34 as well as the calculated torsion angles are depicted in Figure 1.

$\begin{aligned} & \text { Table 1: Calculated relative energy differences of the Z-and } E \text {-config- } \\
& \text { ured isomers of macrocycle } 34 .\end{aligned}$
\begin{tabular}{lll} 
Entry & Method & $\Delta E_{Z-E}(\mathrm{~kJ} / \mathrm{mol})$ \\
\hline 1 & AM1 & 28.7 \\
2 & B3LYP/6-31(d) & 16.4 \\
3 & B3LYP/6-31G(d,p) & 16.4
\end{tabular}

In order to unambiguously identify the double bond configuration of 34, we oxidized this compound with potassium osmate/ NMO to obtain the vicinal diol 35 in $76 \%$ yield (Scheme 8 ). In the case of a $Z$-configured olefin $\mathbf{3 4}$ this dihydroxylation should give a cis-configured diol (meso compound), whereas an $E$-configured olefin 34 would lead to a racemic mixture of the corresponding trans-configured diol. However, due to the symmetry of both vicinal diols a distinction between $c i s$ - and trans-35 $\left(\sigma_{v^{-}}\right.$or $C_{2}$-symmetry respectively) by NMR is still not possible. The resulting diol $\mathbf{3 5}$ was therefore treated with an excess of $(S)$-Mosher's acid chloride to obtain the bis- $(R)$ Mosher ester 36 [74]. TLC analysis and NMR-spectroscopy revealed, that compound $\mathbf{3 6}$ was obtained as a pair of $C_{2}$-symmetric diastereomers and that the obtained diol $\mathbf{3 5}$ was
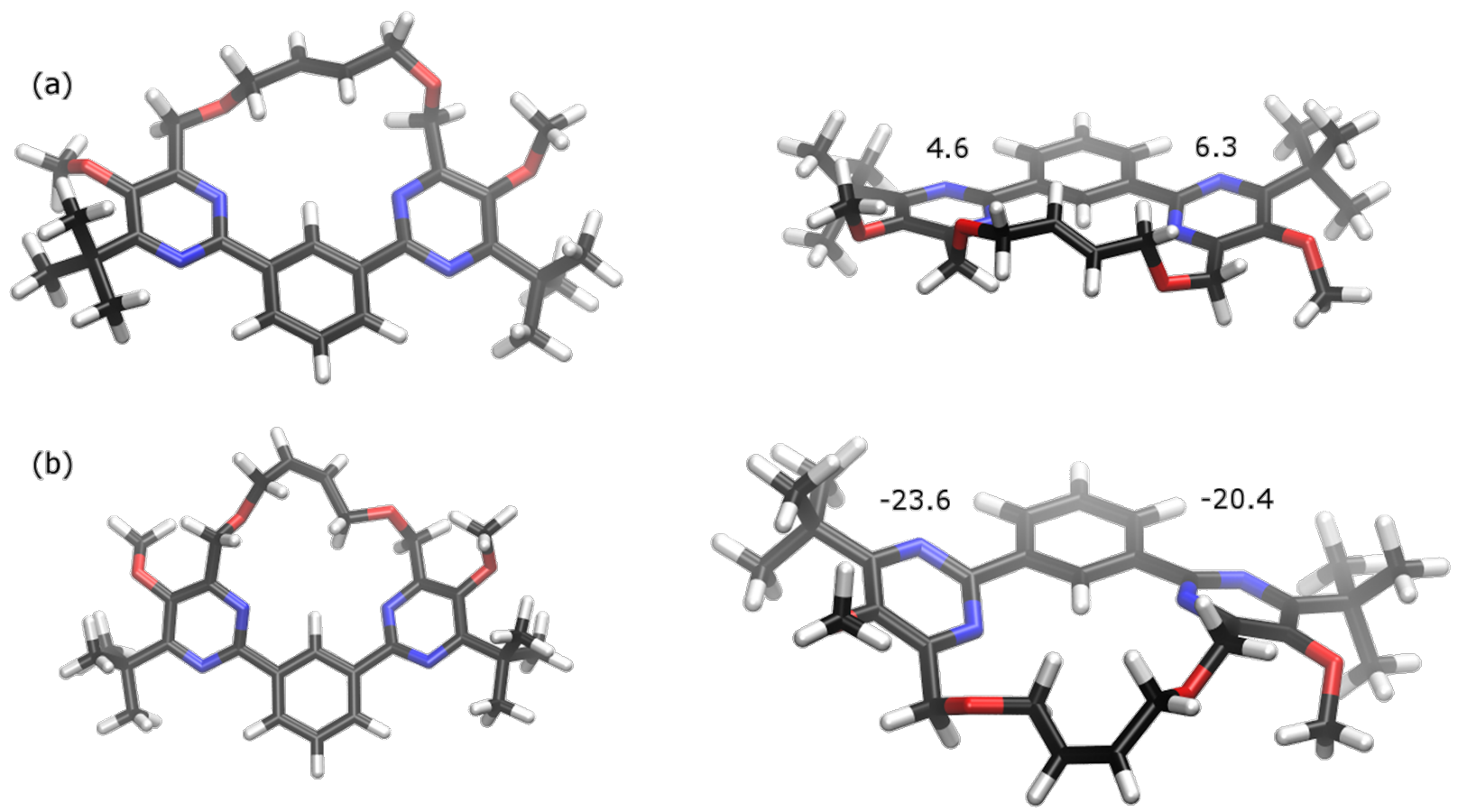

Figure 1: Optimized geometries of (a) E-configured and (b) Z-configured macrocycle 34 at B3LYP/6-31G(d,p) level. The numbers represent the calculated torsion angles between the aromatic rings. 

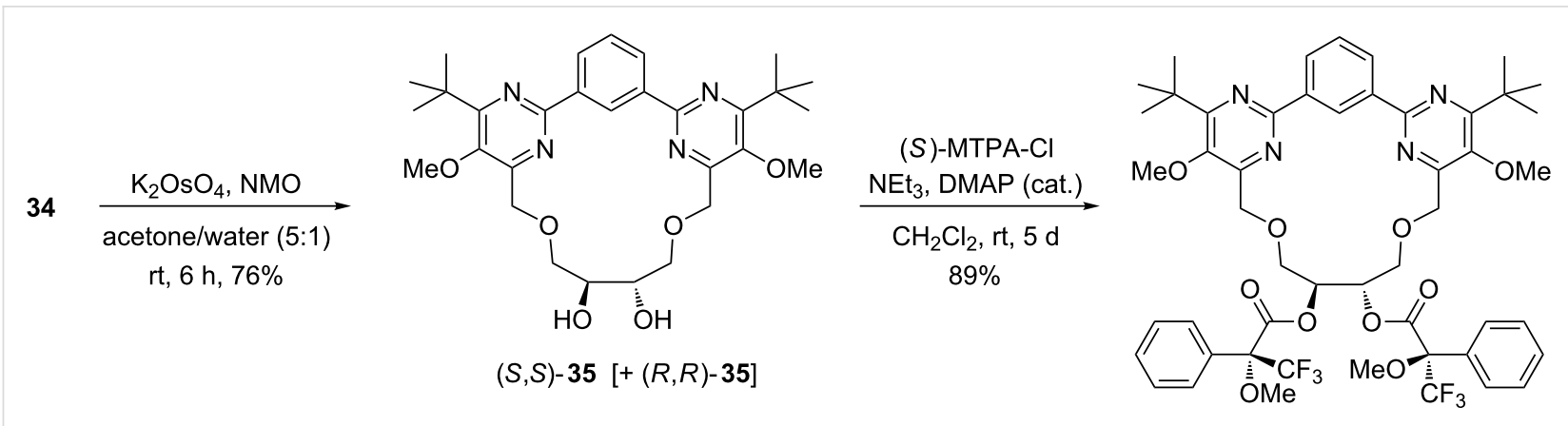

$(R, S, S, R)-36[+(R, R, R, R)-36]$

Scheme 8: Dihydroxylation of the macrocyclic olefin 34 to diol 35 and subsequent esterification to the bis- $(R)-\mathrm{Mosher}$ ester $\mathbf{3 6}$; $(S)-\mathrm{MTPA}-\mathrm{Cl}=(S)-$ 3,3,3-trifluoro-2-methoxy-2-phenylpropanoyl chloride.

in fact a racemic mixture. This observation allowed the conclusion that the RCM reaction of $\mathbf{3 3}$ produced the expected thermodynamically more stable $E$-configured macrocyclic olefin 34. Hence this experimental result is in perfect agreement with the DFT calculations.

\section{Conclusion}

We were able to extend the substrate scope of the Flögel-threecomponent reaction of alkoxyallenes, nitriles and carboxylic acids by successfully utilizing aromatic dicarboxylic acids to prepare three new bis( $\beta$-methoxy- $\beta$-ketoenamides). With these products of a multicomponent reaction we performed cyclizations to rapidly construct symmetrically and unsymmetrically substituted pyridine and pyrimidine derivatives. Hence a very short approach to fairly complex functionalized oligoaromatic systems was established. In addition we exemplarily investigated subsequent transformations of these compounds either by palladium-catalyzed cross-couplings or by oxidations of the 4-methyl groups of the pyrimidine subunits. Although the yields for the crucial initial multicomponent reactions leading to the bis( $\beta$-methoxy- $\beta$-ketoenamides) are only moderate when dicarboxylic acids are used the simplicity of the processes and the diversity of the products accessible is impressive. The described methods allow the preparation of oligo(hetero)aromatic compounds not available by alternative procedures.

\section{Experimental \\ General methods}

Reactions were performed under an atmosphere of argon in flame-dried flasks. Solvents and liquid reagents were added by syringe. $\mathrm{Et}_{2} \mathrm{O}, \mathrm{CH}_{2} \mathrm{Cl}_{2}$ and THF were transferred from a $\mathrm{MB}$ SPS-800-dry solvent system into the reaction vessels. Dry DMF was purchased from Acros Organics and stored in the presence of molecular sieve under an atmosphere of argon. $\mathrm{NEt}_{3}$ was distilled from $\mathrm{CaH}_{2}$ and stored over $\mathrm{KOH}$ under argon. Methoxyallene was prepared from propargylic alcohol in two steps according to literature procedures [34,75]. All other solvents and reagents were purchased from commercial suppliers and were used without further purification. Thin-layer chromatography (TLC) analyses were performed on TLC plates purchased from Merck (silica gel 60, fluorescence indicator F254, $0.25 \mathrm{~mm}$ layer thickness). Products were purified by flash column chromatography on silica gel 60 (230-400 mesh, Macherey-Nagel). NMR spectra were recorded with Bruker (AC 500, AVIII 700) and JEOL (ECX 400, Eclipse 500) instruments. Chemical shifts are reported relative to solvent residual peaks or TMS. Integrals are in accordance with assignments, and coupling constants are given in $\mathrm{Hz}$. All ${ }^{13} \mathrm{C}$ NMR spectra are proton-decoupled. ${ }^{13} \mathrm{C}$ NMR signals of $\mathrm{Nf}$-groups $\left[\mathrm{CF}_{3}\left(\mathrm{CF}_{2}\right)_{3}\right]$ are not given since unambiguous assignment is not possible due to strong splitting by coupling with the ${ }^{19} \mathrm{~F}$ nuclei. IR spectra were measured with a Jasco FT/IR-4100 spectrometer. HRMS analyses were performed with a Varian Ionspec QFT-7 (ESI-FT ICRMS) or an Agilent 6210 (ESI-TOF) instrument. Melting points were measured with a Reichert apparatus (Thermovar) and are uncorrected.

\section{Three-component-reaction of methoxyallene, nitriles} and dicarboxylic acids (typical procedure 1)

To a solution of methoxyallene $(7,2.07 \mathrm{~g}, 29.6 \mathrm{mmol})$ in dry $\mathrm{Et}_{2} \mathrm{O}(25 \mathrm{~mL})$ was added $n$-BuLi $(10.8 \mathrm{~mL}, 27.0 \mathrm{mmol}, 2.5 \mathrm{M}$ in hexanes) at $-50^{\circ} \mathrm{C}$. After 30 min stirring at $-50{ }^{\circ} \mathrm{C}$, the reaction mixture was cooled to $-78{ }^{\circ} \mathrm{C}$ and pivalonitrile $(9,0.752 \mathrm{~g}$, $9.06 \mathrm{mmol})$ in dry $\mathrm{Et}_{2} \mathrm{O}(10 \mathrm{~mL})$ was added to the mixture. After stirring for $4 \mathrm{~h}$ a suspension of diphenic acid (12, $6.54 \mathrm{~g}$, $27.0 \mathrm{mmol})$ in dry $\mathrm{Et}_{2} \mathrm{O}(50 \mathrm{~mL})$ was added. The temperature was allowed to rise to $\mathrm{rt}$ and the mixture was stirred overnight. The reaction was quenched with sat. aq $\mathrm{NaHCO}_{3}$ solution $(25 \mathrm{~mL})$ and the layers were separated. The aqueous layer was extracted with $\mathrm{Et}_{2} \mathrm{O}(3 \times 50 \mathrm{~mL})$ and the combined organic layers were washed with brine $(25 \mathrm{~mL})$, dried with $\mathrm{Na}_{2} \mathrm{SO}_{4}$ and filtered. The solvent was removed under reduced pressure and 
the obtained crude product was purified by column chromatography (silica gel, hexanes/EtOAc $=1: 2)$ to provide bis $(\beta$-ketoenamide) $\mathbf{1 4}$ (1.39 $\mathrm{g}, 28 \%)$ as a pale yellow solid.

$N^{2}, N^{2}$-Bis(4-methoxy-2,2-dimethyl-5-oxohex-3-en-3yl)biphenyl-2,2'-dicarboxamide (14): $\mathrm{mp} 140-143{ }^{\circ} \mathrm{C}$; IR (ATR) v: 3145 (NH), 3040-2835 (=C-H, C-H), $1695(\mathrm{C}=\mathrm{O})$ $1525-1390(\mathrm{C}=\mathrm{C}) \mathrm{cm}^{-1} ;{ }^{1} \mathrm{H} \mathrm{NMR}\left(\mathrm{CDCl}_{3}, 500 \mathrm{MHz}\right) \delta 0.96(\mathrm{~s}$, $18 \mathrm{H}, t-\mathrm{Bu}), 2.09(\mathrm{~s}, 6 \mathrm{H}, \mathrm{Me}), 3.42(\mathrm{~s}, 6 \mathrm{H}, \mathrm{OMe}), 7.07-7.09$ 7.31-7.37, 7.49-7.51 (3 m, 2H, 4H, 2H, Ar), 8.13 (br s, $2 \mathrm{H}$, $\mathrm{NH}) \mathrm{ppm} ;{ }^{13} \mathrm{C} \mathrm{NMR}\left(\mathrm{CDCl}_{3}, 126 \mathrm{MHz}\right) \delta 27.6$ (q, Me), 28.4, 36.5 (q, s, $t-\mathrm{Bu}), 58.8$ (q, OMe), 127.0, 127.9, 129.6, 130.4 (4 d, Ar), 131.9, 136.4, 138.4, 151.0 (4 s, C=C, Ar), 169.5 (s, $\mathrm{CONH}), 200.1(\mathrm{~s}, \mathrm{C}=\mathrm{O})$ ppm; ESI-TOF $(\mathrm{m} / \mathrm{z}):[\mathrm{M}+\mathrm{Na}]^{+}$calcd for $\mathrm{C}_{32} \mathrm{H}_{40} \mathrm{~N}_{2} \mathrm{NaO}_{6}$, 571.2779; found, 571.2783.

\section{Cyclization of $\beta$-ketoenamides to 4-hydroxy- pyridines (typical procedure 2 )}

Bis( $\beta$-ketoenamide) 14 (0.310 g, $0.57 \mathrm{mmol})$ was placed in an ACE-sealed tube and dissolved in DCE $(10 \mathrm{~mL}) . \mathrm{NEt}_{3}$ $(0.40 \mathrm{~mL}, 2.89 \mathrm{mmol})$ and TMSOTf $(0.50 \mathrm{~mL}, 2.76 \mathrm{mmol})$ were added and the resulting mixture was stirred at $90{ }^{\circ} \mathrm{C}$ for $3 \mathrm{~d}$. After cooling to $\mathrm{rt}$ the reaction was quenched with sat. aq $\mathrm{NH}_{4} \mathrm{Cl}$ solution $(10 \mathrm{~mL})$ and the layers were separated. The aqueous layer was extracted with $\mathrm{CH}_{2} \mathrm{Cl}_{2}(3 \times 25 \mathrm{~mL})$ and the combined organic layers were dried with $\mathrm{Na}_{2} \mathrm{SO}_{4}$ and filtered. The solvent was removed under reduced pressure and the obtained crude product was purified by column chromatography (silica gel, EtOAc) to provide bis(4-hydroxypyridine) 18a $(0.174 \mathrm{~g}, 60 \%)$ as a brown liquid and $\mathbf{1 8 b}(54 \mathrm{mg}, 18 \%)$ as pale yellow oil. The products were directly converted into the corresponding nonaflates 19 and 20.

\section{Nonaflation of 4-hydroxypyridines (typical proce- dure 3)}

Bis(4-hydroxypyridine) 18a $(0.805 \mathrm{~g}, 1.57 \mathrm{mmol})$ was dissolved in THF $(25 \mathrm{~mL})$ and $\mathrm{NaH}(0.313 \mathrm{~g}, 7.86 \mathrm{mmol}, 60 \%$ in mineral oil) was added under argon atmosphere. Nonafluorobutanesulfonyl fluoride $(2.35 \mathrm{~g}, 7.79 \mathrm{mmol})$ was added dropwise and the mixture was stirred at $\mathrm{rt}$ for $12 \mathrm{~h}$. After dilution with $\mathrm{Et}_{2} \mathrm{O}(25 \mathrm{~mL})$, the reaction was slowly quenched with ice and water $(25 \mathrm{~mL})$. The layers were separated and the aqueous layer was extracted with $\mathrm{Et}_{2} \mathrm{O}(3 \times 25 \mathrm{~mL})$. The combined organic layers were dried with $\mathrm{Na}_{2} \mathrm{SO}_{4}$, filtered and concentrated to dryness under reduced pressure. The residue was purified by column chromatography (silica gel, hexanes/EtOAc = 9:1 to $4: 1)$ to provide pyridyl nonaflate $19(1.20 \mathrm{~g}, 71 \%)$ as a pale yellow oil.

6,6'-(Biphenyl-2,2'-diyl)bis(2-tert-butyl-3-methoxypyridine6,4-diyl) bisnonaflate (19): IR (ATR) v: 3065-2870 (=C-H,
$\mathrm{C}-\mathrm{H}), 1555-1410(\mathrm{C}=\mathrm{C}) \mathrm{cm}^{-1} ;{ }^{1} \mathrm{H} \mathrm{NMR}\left(\mathrm{CDCl}_{3}, 500 \mathrm{MHz}\right) \delta$ $1.19(\mathrm{~s}, 18 \mathrm{H}, t-\mathrm{Bu}), 3.89(\mathrm{~s}, 6 \mathrm{H}, \mathrm{OMe}), 6.92$ (s, 2H, Py), 7.10 (dd, $J=7.5,1.2 \mathrm{~Hz}, 2 \mathrm{H}, \mathrm{Ar}), 7.30$ (td, $J=7.5,1.4 \mathrm{~Hz}, 2 \mathrm{H}, \mathrm{Ar}$ ), 7.36 (dd, $J=7.5,1.4 \mathrm{~Hz}, 2 \mathrm{H}, \mathrm{Ar}), 7.59$ (dd, $J=7.5,1.2 \mathrm{~Hz}, 2 \mathrm{H}$, Ar) ppm; ${ }^{13} \mathrm{C} \mathrm{NMR}\left(\mathrm{CDCl}_{3}, 126 \mathrm{MHz}\right) \delta 29.1,38.7$ (q, s, $t$-Bu), 61.7 (q, OMe), 115.2 (d, Py), 127.4, 128.6, 130.1, 131.6 (4 d, Ar), 138.2, 140.6 ( $2 \mathrm{~s}, \mathrm{Ar}), 145.3,149.3,153.2,163.7$ (4 s, Py) ppm; ${ }^{19} \mathrm{~F} \mathrm{NMR}\left(\mathrm{CDCl}_{3}, 470 \mathrm{MHz}\right) \delta-80.6(\mathrm{t}, J=9.6 \mathrm{~Hz}, 6 \mathrm{~F}$, $\left.\mathrm{CF}_{3}\right),-109.5\left(\mathrm{t}, J=13.7 \mathrm{~Hz}, 4 \mathrm{~F}, \mathrm{CF}_{2}\right),-120.7,-125.8\left(2 \mathrm{~m}_{\mathrm{c}}\right.$, $4 \mathrm{~F}$ each, $\left.\mathrm{CF}_{2}\right)$ ppm; ESI-TOF $(\mathrm{m} / \mathrm{z}):[\mathrm{M}+\mathrm{Na}]^{+}$calcd for $\mathrm{C}_{40} \mathrm{H}_{34} \mathrm{~F}_{18} \mathrm{~N}_{2} \mathrm{NaO}_{8} \mathrm{~S}_{2}$, 1099.1361; found, 1099.1394.

\section{Cyclization of $\beta$-ketoenamides to pyrimidines (typical procedure 4)}

Bis( $\beta$-ketoenamide) $\mathbf{1 4}(0.162 \mathrm{~g}, 0.296 \mathrm{mmol})$ and $\mathrm{NH}_{4} \mathrm{OAc}$ $(0.365 \mathrm{~g}, 4.73 \mathrm{mmol})$ were placed in an ACE-sealed tube. The mixture was dissolved in $\mathrm{MeOH}(5 \mathrm{~mL})$ and stirred for $2 \mathrm{~d}$ at $90{ }^{\circ} \mathrm{C}$. After addition of $\mathrm{H}_{2} \mathrm{O}(10 \mathrm{~mL})$ and $\mathrm{Et}_{2} \mathrm{O}(20 \mathrm{~mL})$ the layers were separated and the aqueous layer was extracted with $\mathrm{Et}_{2} \mathrm{O}(2 \times 25 \mathrm{~mL})$. The combined organic layers were dried with $\mathrm{Na}_{2} \mathrm{SO}_{4}$, filtered and the solvent was evaporated under reduced pressure. The residue was purified by column chromatography ( silica gel, hexanes/EtOAc $=5: 1$ ) to provide pyrimidines 24a ( $88 \mathrm{mg}, 56 \%$ ) and $24 \mathbf{b}$ (35 $\mathrm{mg}, 23 \%$ ), both as colorless oils.

2,2'-Bis(4-tert-butyl-5-methoxy-6-methylpyrimidin-2yl)biphenyl (24a): IR (ATR) v: 3070-2855 (=C-H, C-H), $1550-1440(\mathrm{C}=\mathrm{C}) \mathrm{cm}^{-1} ;{ }^{1} \mathrm{H} \mathrm{NMR}\left(\mathrm{CDCl}_{3}, 500 \mathrm{MHz}\right) \delta 0.99(\mathrm{~s}$, $18 \mathrm{H}, t-\mathrm{Bu}), 2.28(\mathrm{~s}, 6 \mathrm{H}, \mathrm{Me}), 3.70(\mathrm{~s}, 6 \mathrm{H}, \mathrm{OMe}), 7.30$ (dt, $J=$ 7.7, 1.9 Hz, 2H, Ar), 7.34-7.39 (m, 4H, Ar), 7.70 (dd, $J=7.7$, $1.0 \mathrm{~Hz}, 2 \mathrm{H}, \mathrm{Ar}) \mathrm{ppm} ;{ }^{13} \mathrm{C} \mathrm{NMR}\left(\mathrm{CDCl}_{3}, 126 \mathrm{MHz}\right) \delta 19.7$ (q, $\mathrm{Me}$ ), 28.7, 37.6 (q, s, $t$-Bu), 60.9 (q, OMe), 126.4, 128.7, 130.2, 131.4 (4 d, Ar), 138.4, 142.6 (2 s, Ar), 149.8, 159.3, 159.4, 166.9 (4 s, Py) ppm; ESI-TOF $(\mathrm{m} / z):[\mathrm{M}+\mathrm{H}]^{+}$calcd for $\mathrm{C}_{32} \mathrm{H}_{39} \mathrm{~N}_{4} \mathrm{O}_{2}, 511.3068$; found, 511.3085.

2'-(4-tert-Butyl-5-methoxy-6-methylpyrimidin-2-yl)- $\mathrm{N}$-(4methoxy-2,2-dimethyl-5-oxohex-3-en-3-yl)biphenyl-2carboxamide (24b): IR (ATR) v: $3325(\mathrm{~N}-\mathrm{H}), 3065-2865$ (=C-H, C-H), 1700, $1665(\mathrm{C}=\mathrm{O}), 1550-1445(\mathrm{C}=\mathrm{C}) \mathrm{cm}^{-1}$; ${ }^{1} \mathrm{H} \mathrm{NMR}\left(\mathrm{CDCl}_{3}, 500 \mathrm{MHz}\right) \delta 0.71(\mathrm{~s}, 9 \mathrm{H}, t-\mathrm{Bu}), 1.26(\mathrm{~s}, 9 \mathrm{H}$, $t$-Bu), 2.31, 2.33 (2 s, 3H each, Me), 3.45, $3.70(2 \mathrm{~s}, 3 \mathrm{H}$ each, OMe), 6.64 (dd, $J=7.5,1.0 \mathrm{~Hz}, 1 \mathrm{H}, \mathrm{Ar}), 7.07,7.25(2 \mathrm{dt}, J=$ 7.5, 1.2 Hz, 1H each, Ar), 7.32 (dd, $J=7.5,1.2 \mathrm{~Hz}, 1 \mathrm{H}, \mathrm{Ar})$, 7.39 (dt, $J=7.5,1.8 \mathrm{~Hz}, 1 \mathrm{H}, \mathrm{Ar}), 7.43$ (dt, $J=7.5,1.0 \mathrm{~Hz}, 1 \mathrm{H}$, Ar), 7.50 (dd, $J=7.8,1.2 \mathrm{~Hz}, 1 \mathrm{H}, \mathrm{Ar}), 7.91$ (dd, $J=7.8,1.8 \mathrm{~Hz}$, $1 \mathrm{H}, \mathrm{Ar}), 8.40$ (br s, $1 \mathrm{H}, \mathrm{NH}) \mathrm{ppm} ;{ }^{13} \mathrm{C} \mathrm{NMR}\left(\mathrm{CDCl}_{3}, 126\right.$ $\mathrm{MHz}) \delta 19.2$ (q, Me), 27.2 (q, Me), 28.1, 29.2, 35.9, 37.9 (2 q, 2 $\mathrm{s}, t$-Bu), 58.9, 61.0 (2 q, OMe), 126.8, 127.9, 128.0, 128.5, 129.0, 129.4, 130.3, 130.7, 131.0 ( $8 \mathrm{~d}, \mathrm{~s}, \mathrm{Ar},=\mathrm{C}), 137.5,138.4$, 
138.9, 140.5, 150.1 (5 s, Ar, =C), 150.4, 159.6, 160.0, 168.4 (4 $\mathrm{s}, \mathrm{Py}), 169.3$ (s, CONH), 199.8 (s, C=O) ppm; ESI-TOF $(\mathrm{m} / \mathrm{z})$ : $[\mathrm{M}+\mathrm{Na}]^{+}$calcd for $\mathrm{C}_{32} \mathrm{H}_{34} \mathrm{~N}_{3} \mathrm{NaO}_{4}, 552.2833$; found, 552.2844 .

\section{Supporting Information}

\section{Supporting Information File 1}

Additional experimental procedures and analytical data, as well as copies of NMR spectra of representative examples. [http://www.beilstein-journals.org/bjoc/content/ supplementary/1860-5397-10-37-S1.pdf]

\section{Acknowledgements}

Generous support of this work by the Alexander von Humboldt Foundation by a postdoctoral research fellowship for M. K. B. and by Bayer HealthCare is most gratefully acknowledged. A postdoctoral research fellowship for M. D. by BECAS CHILE and his support by the Dierks-von-Zweck-Stiftung is gratefully acknowledged. We also thank Dr. R. Zimmer for discussions and assistance during preparation of this manuscript.

\section{References}

1. Zhu, J.; Bienaymé, H., Eds. Multicomponent Reactions; Wiley-VCH: Weinheim, Germany, 2005.

2. Tietze, L. F.; Brasche, G.; Gericke, K. M. Domino Reactions in Organic Synthesis; Wiley-VCH: Weinheim, Germany, 2006.

3. D'Souza, D. M.; Müller, T. J. J. Chem. Soc. Rev. 2007, 36, 1095-1108. doi:10.1039/b608235c

4. Brauch, S.; van Berkel, S. S.; Westermann, B. Chem. Soc. Rev. 2013, 42, 4948-4962. doi:10.1039/c3cs35505e

5. Simon, C.; Constantieux, T.; Rodriguez, J. Eur. J. Org. Chem. 2004, 4957-4980. doi:10.1002/ejoc.200400511

6. Eckert, H. Molecules 2012, 17, 1074-1102. doi:10.3390/molecules17011074

7. Ruijter, E.; Scheffelaar, R.; Orru, R. V. A. Angew. Chem., Int. Ed. 2011, 50, 6234-6246. doi:10.1002/anie.201006515 Angew Chem. 2011, 123, 6358-6371. doi:10.1002/ange.201006515

8. Hantzsch, A. Justus Liebigs Ann. Chem. 1882, 215, 1-82. doi:10.1002/jlac.18822150102

9. Biginelli, P. Gazz. Chim. Ital. 1983, 23, 360-416.

10. Evdokimov, N. M.; Kireev, A. S.; Yakovenko, A. A.; Antipin, M. Yu.; Magedov, I. V.; Kornienko, A. J. Org. Chem. 2007, 72, 3443-3453. doi:10.1021/jo070114u

11. Sasada, T.; Sakai, N.; Konakahara, T. J. Org. Chem. 2008, 73, 6905-6908. doi:10.1021/j0801090h

12. Barluenga, J.; Jiménez-Aquino, A.; Fernández, M. A.; Aznar, F.; Valdés, C. Tetrahedron 2008, 64, 778-786. doi:10.1016/j.tet.2007.10.112

13. Da-Qing, S.; Hao, Y. Synth. Commun. 2009, 39, 2481-2491. doi:10.1080/00397910802656034

14. Guo, K.; Thompson, M. J.; Chen, B. J. Org. Chem. 2009, 74, 6999-7006. doi:10.1021/jo901232b
15. Sha, F.; Huang, X. Angew. Chem., Int. Ed. 2009, 48, 3458-3461. doi:10.1002/anie.200900212

Angew. Chem. 2009, 121, 3510-3513. doi:10.1002/ange.200900212

16. Chen, M. Z.; Micalizio, G. C. J. Am. Chem. Soc. 2012, 134, 1352-1356. doi:10.1021/ja2105703

17. Al-Awadi, N. A.; Ibrahim, M. R.; Elnagdi, M. H.; John, E.; Ibrahim, Y. A. Beilstein J. Org. Chem. 2012, 8, 441-447. doi:10.3762/bjoc.8.50

18. Sha, F.; Wu, L.; Huang, X. J. Org. Chem. 2012, 77, 3754-3765. doi:10.1021/jo300072x

19. Zheng, L.; Ju, J.; Bin, Y.; Hua, R. J. Org. Chem. 2012, 77, 5794-5800. doi:10.1021/jo3010414

20. He, Z.; Dobrovolsky, D.; Trinchera, P.; Yudin, A. K. Org. Lett. 2013, 15 , 334-337. doi:10.1021/ol303246b

21. Stonehouse, J. P.; Chekmarev, D. S.; Ivanova, N. V.; Lang, S.; Pairaudeau, G.; Smith, N.; Stocks, M. J.; Sviridov, S. I.; Utkina, L. M. Synlett 2008, 100-104. doi:10.1055/s-2007-1000839

22. Sasada, T.; Moriuchi, M.; Sakai, N.; Konakahara, T. Eur. J. Org. Chem. 2009, 5738-5743. doi:10.1002/ejoc.200900639

23. Sasada, T.; Kobayashi, F.; Sakai, N.; Konakahara, T. Org. Lett. 2009, 11, 2161-2164. doi:10.1021/ol900382j

24. Hekmatshoar, R.; Kenary, G. N.; Sadjadi, S.; Beheshtiha, Y. S. Synth. Commun. 2010, 40, 2007-2013. doi:10.1080/00397910903219385

25. Wan, J.-P.; Liu, Y. Synthesis 2010, 3943-3953. doi:10.1055/s-0030-1258290

26. Zonouzi, A.; Biniaz, M.; Mirzazadeh, R.; Talebi, M.; Ng, S. W. Heterocycles 2010, 81, 1271-1278. doi:10.3987/com-10-11929

27. Majumder, S.; Odom, A. L. Tetrahedron 2010, 66, 3152-3158. doi:10.1016/j.tet.2010.02.066

28. Sedenkova, K. N.; Averina, E. B.; Grishin, Y. K.; Kutateladze, A. G.; Rybakov, V. B.; Kuznetsova, T. S.; Zefirov, N. S. J. Org. Chem. 2012, 77, 9893-9899. doi:10.1021/jo301880m

29. You, X.; Yu, S.; Liu, Y. Organometallics 2013, 32, 5273-5276. doi:10.1021/om400880r

30. Reddy, L. S.; Reddy, T. R.; Reddy, N. C. G.; Mohan, R. B.; Lingappa, Y. Synthesis 2013, 45, 75-84. doi:10.1055/s-0032-1316814

31. Yavari, I.; Nematpour, M. Synlett 2013, 24, 165-168. doi:10.1055/s-0032-1317951

32. Yang, K.; Xiang, J.; Bao, G.; Dang, Q.; Bai, X. ACS Comb. Sci. 2013, 15, 519-524. doi:10.1021/co400086u

33. Gers, C. F.; Rosellen, J.; Merkul, E.; Müller, T. J. J. Beilstein J. Org. Chem. 2011, 7, 1173-1181. doi:10.3762/bjoc.7.136

34. Zimmer, R. Synthesis 1993, 165-178. doi:10.1055/s-1993-25823 And references cited therein.

35. Krause, N.; Hashmi, A. S. K., Eds. Modern Allene Chemistry; Wiley-VCH: Weinheim, Germany, 2004.

36. Brasholz, M.; Reissig, H.-U.; Zimmer, R. Acc. Chem. Res. 2009, 42, 45-56. doi:10.1021/ar800011h

37. Lechel, T.; Reissig, H.-U. Pure Appl. Chem. 2010, 82, 1835-1844. doi:10.1351/pac-con-09-09-06

38. Flögel, O.; Dash, J.; Brüdgam, I.; Hartl, H.; Reissig, H.-U. Chem.-Eur. J. 2004, 10, 4283-4290. doi:10.1002/chem.200400322

39. Dash, J.; Lechel, T.; Reissig, H.-U. Org. Lett. 2007, 9, 5541-5544. doi:10.1021/ol702468s

40. Eidamshaus, C.; Reissig, H.-U. Adv. Synth. Catal. 2009, 351, 1162-1166. doi:10.1002/adsc.200800789

41. Lechel, T.; Dash, J.; Eidamshaus, C.; Brüdgam, I.; Lentz, D.; Reissig, H.-U. Org. Biomol. Chem. 2010, 8, 3007-3014. doi:10.1039/B925468D 
42. Lechel, T.; Dash, J.; Hommes, P.; Lentz, D.; Reissig, H.-U. J. Org. Chem. 2010, 75, 726-732. doi:10.1021/jo9022183

43. Bera, M. K.; Reissig, H.-U. Synthesis 2010, 2129-2138. doi:10.1055/s-0029-1218787

44. Eidamshaus, C.; Kumar, R.; Bera, M. K.; Reissig, H.-U. Beilstein J. Org. Chem. 2011, 7, 962-975. doi:10.3762/bjoc.7.108

45. Lechel, T.; Dash, J.; Brüdgam, I.; Reissig, H.-U. Eur. J. Org. Chem. 2008, 3647-3655. doi:10.1002/ejoc.200800398

46. Lechel, T.; Lentz, D.; Reissig, H.-U. Chem.-Eur. J. 2009, 15 , 5432-5435. doi:10.1002/chem.200900386

47. Lechel, T.; Gerhard, M.; Trawny, D.; Brusilowskij, B.; Schefzig, L.; Zimmer, R.; Rabe, J. P.; Lentz, D.; Schalley, C. A.; Reissig, H.-U. Chem.-Eur. J. 2011, 17, 7480-7491. doi:10.1002/chem.201100382

48. Lechel, T.; Möhl, S.; Reissig, H.-U. Synlett 2009, 1059-1062. doi:10.1055/s-0028-1088220

49. Lechel, T.; Reissig, H.-U. Eur. J. Org. Chem. 2010, 2555-2564. doi:10.1002/ejoc.201000056

50. Zimmer, R.; Lechel, T.; Rancan, G.; Bera, M. K.; Reissig, H.-U. Synlett 2010, 1793-1796. doi:10.1055/s-0030-1258088

51. Dash, J.; Reissig, H.-U. Chem.-Eur. J. 2009, 15, 6811-6814. doi:10.1002/chem.200900939

52. Hommes, P.; Jungk, P.; Reissig, H.-U. Synlett 2011, 2311-2314. doi:10.1055/s-0030-1260304

53. Eidamshaus, C.; Reissig, H.-U. Eur. J. Org. Chem. 2011, 6056-6069. doi:10.1002/ejoc.201100681

54. Högermeier, J.; Reissig, H.-U. Adv. Synth. Catal. 2009, 351, 2747-2763. doi:10.1002/adsc.200900566

55. Bera, M. K.; Hommes, P.; Reissig, H.-U. Chem.-Eur. J. 2011, 17, 11838-11843. doi:10.1002/chem.201101739

56. Eidamshaus, C.; Hommes, P.; Reissig, H.-U. Synlett 2012, 23 , 1670-1674. doi:10.1055/s-0031-1290398

57. Gholap, S. L.; Hommes, P.; Neuthe, K.; Reissig, H.-U. Org. Lett. 2013, 15, 318-321. doi:10.1021/ol303231c

58. Bera, M. K.; Gholap, S. L.; Hommes, P.; Neuthe, K.; Trawny, D.; Rabe, J. P.; Lentz, D.; Zimmer, R.; Reissig, H.-U. Adv. Synth. Catal. 2013, 355, 3463-3474. doi:10.1002/adsc.201300613

59. Boekelheide, V.; Linn, W. J. J. Am. Chem. Soc. 1954, 76, 1286-1291. doi:10.1021/ja01634a026

60. Galatsis, P. Boekelheide Reaction. In Name Reactions in Heterocyclic Chemistry; Li, J.-J.; Corey, E. J., Eds.; John Wiley \& Sons Inc.: Hoboken, New Jersey, 2005; pp 340-349.

61. Fortea, J. J. Prakt. Chem. 1975, 317, 705-711. doi:10.1002/prac.19753170502

62. Sakamoto, T.; Yoshizawa, H.; Kaneda, S.; Yamanaka, H. Chem. Pharm. Bull. 1984, 32, 728-732. doi:10.1248/cpb.32.728

63. Blake, J. F.; Xu, R.; Bencsik, J. R.; Xiao, D.; Kallan, N. C.; Schlachter, S.; Mitchell, I. S.; Spencer, K. L.; Banka, A. L.; Wallace, E. M.; Gloor, S. L.; Martinson, M.; Woessner, R. D.; Vigers, G. P. A.; Brandhuber, B. J.; Liang, J.; Safina, B. S.; Li, J.; Zhang, B.; Chabot, C.; Do, S.; Lee, L.; Oeh, J.; Sampath, D.; Lee, B. B.; Lin, K.; Liederer, B. M.; Skelton, N. J. J. Med. Chem. 2012, 55, 8110-8127. doi:10.1021/jm301024w

64. Lehn, J.-M.; Regnouf de Vains, J.-B. Tetrahedron Lett. 1989, 30 , 2209-2212. doi:10.1016/S0040-4039(00)99650-3

65. Tikhonov, A. Y.; Volodarskii, L. B.; Vakolova, O. A.; Podgornaya, M. I. Chem. Heterocycl. Compd. 1981, 17, 89-95. doi:10.1007/bf00507100

66. Waitkins, G. R.; Clark, C. W. Chem. Rev. 1945, 36, 235-289. doi:10.1021/cr60115a001

67. Rabjohn, N. Org. React. 1976, 24, 261-415.
68. Tagawa, Y.; Yamashita, K.; Higuchi, Y.; Goto, Y. Heterocycles 2003, 60, 953-957. doi:10.3987/COM-02-9702

69. Grubbs, R. H., Ed. Handbook of Metathesis; Wiley-VCH: Weinheim, Germany, 2003.

70. Lee, C. W.; Grubbs, R. H. Org. Lett. 2000, 2, 2145-2147. doi:10.1021/ol006059s

71. Heckrodt, T. J.; Singh, R. Synth. Commun. 2011, 42, 2854-2865. doi:10.1080/00397911.2011.570891

72. Marx, V. M.; Herbert, M. B.; Keitz, B. K.; Grubbs, R. H. J. Am. Chem. Soc. 2013, 135, 94-97. doi:10.1021/ja311241q

73. Prunet, J. Angew. Chem., Int. Ed. 2003, 42, 2826-2830. doi:10.1002/anie.200301628 Angew. Chem. 2003, 115, 2932-2936. doi:10.1002/ange.200301628

74. Dale, J. A.; Mosher, H. S. J. Am. Chem. Soc. 1973, 95, 512-519. doi:10.1021/ja00783a034

75. Hoff, S.; Brandsma, L.; Arens, J. F. Recl. Trav. Chim. Pays-Bas 1968, 87, 916-924. doi:10.1002/recl.19680870807

\section{License and Terms}

This is an Open Access article under the terms of the Creative Commons Attribution License (http://creativecommons.org/licenses/by/2.0), which permits unrestricted use, distribution, and reproduction in any medium, provided the original work is properly cited.

The license is subject to the Beilstein Journal of Organic Chemistry terms and conditions:

(http://www.beilstein-journals.org/bjoc)

The definitive version of this article is the electronic one which can be found at: doi:10.3762/bjoc. 10.37 